Psychother Psychosom 2012;81:127-129

DOI: $10.1159 / 000329996$

\section{Coping Styles in Chronic Fatigue Syndrome: Findings from a Population-Based Study}

\author{
Urs M. Natera, d, Elizabeth Maloney a , Jin-Mann S. Lin ${ }^{\mathrm{b}}$, \\ Christine Heim ${ }^{c}$, William C. Reeves ${ }^{b}$ \\ ${ }^{a}$ Chronic Viral Diseases Branch, Division of High-Consequence \\ Pathogens and Pathology (proposed), National Center for \\ Emerging and Zoonotic Infectious Diseases, Centers for Disease \\ Control \& Prevention, ${ }^{b}$ Mental Health Surveillance, Public \\ Health Surveillance Program Office, Office of Surveillance, \\ Epidemiology and Laboratory Services, Centers for Disease \\ Control \& Prevention, and ${ }^{\mathrm{C} D e p a r t m e n t}$ of Psychiatry \& \\ Behavioral Sciences, Emory University School of Medicine, \\ Atlanta, Ga., USA; ${ }^{\mathrm{d}}$ Clinical Biopsychology, Department of \\ Psychology, University of Marburg, Marburg, Germany
}

Chronic fatigue syndrome (CFS) is a common and debilitating illness [1]. As yet the pathophysiology of CFS remains inchoate, so pharmacologic management aims to alleviate symptoms and is not curative. Cognitive-behavioral therapy and graded exercise therapy appear to be the most effective treatments for CFS [2]. Such therapies require that patients understand, adhere to and practice specific activities to manage their thoughts and expenditure of physical energy. This necessary understanding and commitment are heavily impacted by patients' coping styles and concomitant psychopathology. In a previous population-based study, we found that people with CFS were significantly more likely to use maladaptive everyday coping strategies than non-fatigued matched controls [3]. In another population-based study, we found that about $60 \%$ of people with CFS suffered psychiatric comorbidity; in particular affective and anxiety disorders [4], and displayed maladaptive personality styles [5]. In the current population-based study, we examined coping styles in CFS and how these are affected by depression and anxiety.

Study participants were identified during a survey of unwellness in metropolitan, urban, and rural populations of Georgia. Details are given in Reeves et al. [1]. All participants gave informed consent. To identify medical conditions considered exclusionary for CFS [6], participants completed past medical history questionnaires underwent a standardized physical examination, and provided blood and urine specimens for routine clinical laboratory screening. To identify exclusionary psychiatric conditions, participants completed the SCID, a standardized interview [7]. We diagnosed CFS as recommended by the International CFS Study Group [6]. Well controls had no medical or psychiatric conditions considered exclusionary for CFS. We included 113 CFS suffers and 124 'well' controls in our analyses.
We used the Ways of Coping Questionnaire (WCQ) to measure coping styles [8]. This 66-item self-report questionnaire comprises a wide range of thoughts and acts that people utilize to deal with the internal or external demands of specific stressful encounters. Coping strategies are summarized in eight scales (table 1). The Self-Rating Depression Scale was used to quantify depressive symptoms, based on 20 items [9]. Anxiety was assessed using the State Anxiety Inventory that provides a continuous score based on 20 items [10].

Data were tested for normal distribution by the KolmogorovSmirnov test. For metric data, group differences between CFS and well subjects were analyzed with general linear models. Homogeneity of variance was assessed using Levene's test. Analyses were two-tailed with the level of significance set at $p<0.05$.

Demographic features were similar among participants with CFS and well controls. The two groups differed significantly regarding depressive symptoms (CFS: mean (95\% CI) = $70.5(41.5-$ 99.5), well: 37.0 (21.5-52.5); $\mathrm{p}<0.001)$ and anxiety (CFS: 63.8 (34.5-93.1), well: 25.7 (24.7-26.8); $\mathrm{p}<0.001)$

Coping strategies also differed significantly between the two groups (table 1). A multivariate analysis indicated an overall difference $\left(F_{8,218}=5.97 ; p<0.001 ; \eta^{2}=0.18\right)$. Relative to the well group, those with CFS had statistically significantly higher mean scores in the escape-avoidance, confrontive, distancing, self-controlling, and accepting responsibility coping styles. All differences remained significant after controlling for age, sex, race, and education level. Effect sizes were of medium strength for those coping styles that differed significantly, with distancing being the exception. We also computed correlations between coping styles, illness duration and fatigue levels (as measured by the Multidimensional Fatigue Inventory [11]) in CFS, but did not observe any significant correlations.

We further adjusted for state anxiety and symptoms of depression for comparisons of escape-avoidance, confrontive, distancing, self-controlling, and accepting responsibility coping styles between groups. In this fully adjusted model, all differences in scores for these coping styles between study groups remained significant, except for distancing. Neither symptoms of depression nor anxiety were significantly associated with these coping styles (all p >0.05).

This survey of metropolitan, urban, and rural Georgia populations corroborated our previous findings from the general population of Wichita [3] inasmuch as persons with CFS were significantly more likely to employ maladaptive coping strategies than well controls. Several other studies have documented dysfunctional or maladaptive coping styles in CFS [12]. Our current study circumvented the various methodological problems associated with recruiting participants from primary or tertiary care, which may increase the likelihood that our findings are generalizable to the entire population of persons with CFS, not just those who have obtained medical care. In accordance with our previous study,

\section{KARGER}

Fax +41613061234 E-Mail karger@karger.ch www.karger.com
C 2012 S. Karger AG, Basel

$0033-3190 / 12 / 0812-0127 \$ 38.00 / 0$ 
Table 1. Coping styles in CFS cases and well controls

\begin{tabular}{|c|c|c|c|c|c|}
\hline \multirow[t]{2}{*}{ Coping strategies } & \multicolumn{2}{|c|}{ WCQ summary scores $(95 \% \mathrm{CI})$} & \multirow[t]{2}{*}{ F values with d.f. } & \multirow[t]{2}{*}{$\mathrm{p}$ values } & \multirow{2}{*}{$\begin{array}{l}\text { Effect } \\
\text { size } \eta^{2}\end{array}$} \\
\hline & $\begin{array}{l}\text { CFS } \\
(n=113)\end{array}$ & $\begin{array}{l}\text { well controls } \\
(\mathrm{n}=124)\end{array}$ & & & \\
\hline Escape-avoidance & $14.2(13.3-15.1)$ & $10.9(10.4-11.4)$ & $\begin{array}{l}\mathrm{F}(1,225)=32.51 \\
\mathrm{~F}(1,223)=27.95\end{array}$ & $\begin{array}{l}<0.001^{1} \\
<0.001^{2}\end{array}$ & $\begin{array}{l}0.13 \\
0.11\end{array}$ \\
\hline Confrontive coping & $12.3(11.6-13.0)$ & $9.8(9.3-10.3)$ & $\begin{array}{l}\mathrm{F}(1,225)=29.24 \\
\mathrm{~F}(1,223)=24.41\end{array}$ & $\begin{array}{l}<0.001^{1} \\
<0.001^{2}\end{array}$ & $\begin{array}{l}0.12 \\
0.10\end{array}$ \\
\hline Distancing & $11.6(10.9-12.2)$ & $10.4(9.9-10.9)$ & $\begin{array}{l}\mathrm{F}(1,225)=4.86 \\
\mathrm{~F}(1,223)=3.64\end{array}$ & $\begin{array}{l}0.028^{1} \\
0.058^{2}\end{array}$ & $\begin{array}{l}0.02 \\
0.02\end{array}$ \\
\hline Self-controlling & $16.3(15.6-17.1)$ & $14.6(13.9-15.4)$ & $\begin{array}{l}\mathrm{F}(1,225)=13.52 \\
\mathrm{~F}(1,223)=11.14\end{array}$ & $\begin{array}{r}<0.001^{1} \\
0.001^{2}\end{array}$ & $\begin{array}{l}0.06 \\
0.05\end{array}$ \\
\hline Seeking social support & $12.8(12.1-13.5)$ & $12.3(11.6-13.0)$ & $\begin{array}{l}\mathrm{F}(1,225)=1.88 \\
\mathrm{~F}(1,223)=2.08\end{array}$ & $\begin{array}{l}0.171^{1} \\
0.151^{2}\end{array}$ & $\begin{array}{l}0.01 \\
0.01\end{array}$ \\
\hline Accepting responsibility & $8.0(7.4-8.6)$ & $6.2(5.8-6.7)$ & $\begin{array}{l}\mathrm{F}(1,225)=19.19 \\
\mathrm{~F}(1,223)=15.97\end{array}$ & $\begin{array}{l}<0.001^{1} \\
<0.001^{2}\end{array}$ & $\begin{array}{l}0.08 \\
0.07\end{array}$ \\
\hline Planful problem solving & $14.3(13.5-15.0)$ & $13.9(13.1-14.7)$ & $\begin{array}{l}\mathrm{F}(1,225)=1.44 \\
\mathrm{~F}(1,223)=1.09\end{array}$ & $\begin{array}{l}0.232^{1} \\
0.297^{2}\end{array}$ & $\begin{array}{l}0.01 \\
0.01\end{array}$ \\
\hline Positive reappraisal & $15.2(14.2-16.1)$ & $14.5(13.5-15.4)$ & $\begin{array}{l}\mathrm{F}(1,225)=0.95 \\
\mathrm{~F}(1,223)=0.72\end{array}$ & $\begin{array}{l}0.332^{1} \\
0.397^{2}\end{array}$ & $\begin{array}{l}0.004 \\
0.003\end{array}$ \\
\hline
\end{tabular}

${ }^{1}$ Age, sex, race, and education level are covariates.

${ }^{2}$ Age, sex, race, education level, depressivity, and anxiety are covariates.

escape-avoidance emerged as the most prominent coping style in CFS. People utilizing this coping style incorporated behavioral efforts to escape or avoid a specific problem (item example from the WCQ when asked about how the response to a recent stressful event was: 'I tried to make myself feel better by eating, drinking, smoking, using drugs or medications, etc.'). Further, confrontive coping, which was also used more often in CFS, is characterized by aggressive efforts to alter a stressful situation ('I expressed anger to the person who caused the problem'). High scores in selfcontrolling coping indicate increased efforts to regulate an individual's emotions ('I tried to keep my feelings to myself'), and, finally, high scores in accepting responsibility indicate that someone acknowledges his or her own role in the problem ('I criticized or lectured myself'). As these coping styles are not inherently negative, it can be assumed that they can turn maladaptive when predominantly used in solving everyday problems. Also, in some instances predominant use of some coping styles may even be an adaptive reaction to the experience of a severe stressor. This needs to be examined in further analyses. A further limitation is that no statement can be made on whether the differences in coping styles between CFS patients and well controls play a role in the causation of CFS and/or might be a consequence of CFS. Also, another community-based study of chronic fatigue showed that no differences existed with regard to coping styles between individuals with CFS and healthy controls [13]. However, measurement of coping differed from our study, rendering it difficult to compare findings between the two studies. Finally, the question arises of whether coping patterns found in CFS are similar to other chronic illnesses. Although some studies indicate that this might not be the case [14], future studies should ascertain whether coping styles found in our study are specific for CFS or not.

Importantly, we found that discrepancies between the two groups could not be explained by the presence of depressive symptoms or anxiety, despite of high levels of psychopathology in individuals with CFS.

Our findings have important consequences for treatment strategies in CFS. Interventions such as cognitive-behavioral therapy and graded exercise therapy aim at improving adaptive coping capabilities. These treatment approaches will most likely be successful without taking concomitant psychopathology into account. Future studies should now incorporate longitudinal designs in order to determine causal pathways between coping and illness.

\section{Acknowledgements}

The authors have no conflicts of interest to declare. C.H. has received/receives funding or fees from NIMH, NARSAD, ADAA, Center for Behavioral Neuroscience/SNF, CDC, Eli Lilly, Novartis, and CeNeRx. The findings and conclusions in this report are those of the authors and do not necessarily represent the views of the funding agency. 


\section{References}

$\checkmark 1$ Reeves WC, Jones JF, Maloney E, Heim C, Hoaglin DC, Boneva RS, Morrissey M, Devlin R: Prevalence of chronic fatigue syndrome in metropolitan, urban, and rural georgia. Popul Health Metr 2007;5:5.

-2 Knoop H, Bleijenberg G, Gielissen MF, van der Meer JW, White PD: Is a full recovery possible after cognitive behavioural therapy for chronic fatigue syndrome? Psychother Psychosom 2007;76:171-176.

- 3 Nater UM, Wagner D, Solomon L, Jones JF, Unger ER, Papanicolaou DA, Reeves WC, Heim C: Coping styles in people with chronic fatigue syndrome identified from the general population of Wichita, KS. J Psychosom Res 2006;60:567-573.

-4 Nater UM, Lin JM, Maloney EM, Jones JF, Tian H, Boneva RS, Raison CL, Reeves WC, Heim C: Psychiatric comorbidity in persons with chronic fatigue syndrome identified from the Georgia population. Psychosom Med 2009;71:557-565.

5 Nater UM, Jones JF, Lin JM, Maloney E, Reeves WC, Heim C: Personality features and personality disorders in chronic fatigue syndrome: a population-based study. Psychother Psychosom 2010;79:312-318.

-6 Reeves WC, Lloyd A, Vernon SD, Klimas N, Jason LA, Bleijenberg G, Evengard B, White PD, Nisenbaum R, Unger ER: Identification of ambiguities in the 1994 chronic fatigue syndrome research case definition and recommendations for resolution. BMC Health Serv Res 2003;3:25.

7 First MB, Spitzer RL, Gibbon M, Williams JBW: Structured clinical interview for DSM-IV-TR axis I disorders, research version. New York, Biometrics Research, New York State Psychiatric Institute, 2002.
8 Folkman S, Lazarus R: Manual for the ways of coping questionnaire. Palo Alto, Consulting Psychologists Press, 1988.

-9 Zung WWK: A self-rating depression scale. Arch Gen Psychiatry 1965; 12:63-70.

10 Spielberger CD, Gorsuch RL, Lushene RE: STAI, Manual for the StateTrait-Anxiety-Inventory. Palo Alto, Consulting Psychologists Press, 1970

11 Smets EM, Garssen B, Bonke B, De Haes JC: The Multidimensional Fatigue Inventory (MFI) psychometric qualities of an instrument to assess fatigue. J Psychosom Res 1995;39:315-325.

12 Ax S, Gregg VH, Jones D: Coping and illness cognitions: chronic fatigue syndrome. Clin Psychol Rev 2001;21:161-182.

13 Jason LA, Witter E, Torres-Harding S: Chronic fatigue syndrome, coping, optimism and social support. J Mental Health 2003;12:109-118.

14 Creswell C, Chalder T: Defensive coping styles in chronic fatigue syndrome. J Psychosom Res 2001;51:607-610.

William C. Reeves, MD, MSc

Public Health Surveillance Program Office, Mail Stop E-33

Centers for Disease Control and Prevention

1600 Clifton Road NE, Atlanta, GA 30333 (USA)

Tel. +1 404498 6521, E-Mail wcr1@cdc.gov 